\title{
An Empirical Study on Employment Changes in China-Based on VAR Model
}

\author{
Jianjun Zhou \\ Business School, East China University of Political Science and Law, Shanghai, China \\ Email: zjjqw66@163.com
}

How to cite this paper: Zhou, J. J. (2020) An Empirical Study on Employment Changes in China-Based on VAR Model. American Journal of Industrial and Business Management, 10, 1250-1262. https://doi.org/10.4236/ajibm.2020.107083

Received: June 17, 2020

Accepted: July 21, 2020

Published: July 24, 2020

Copyright $\odot 2020$ by author(s) and Scientific Research Publishing Inc. This work is licensed under the Creative Commons Attribution International License (CC BY 4.0).

http://creativecommons.org/licenses/by/4.0/

(c) (i) Open Access

\begin{abstract}
The paper aimed to empirically study the dynamic mechanism of China's employment changes, using the VAR model to use China's 1981-2019 time series data to construct economic growth, industrial structure changes and capital investment indicators. Research shows that: China's economic growth can promote labor employment; the proportion of secondary industry and tertiary industry can promote labor employment, but the employment effect of tertiary industry is higher than that of secondary industry; capital investment has a significant negative effect on the employment elasticity coefficient. At the same time, in order to quantitatively study the impact of various variables on changes in the employment structure, specific consideration is given to the short-term and long-term phases. Finally, based on the conclusion of the study, the corresponding policy recommendations are put forward.
\end{abstract}

\section{Keywords}

Employment Change, VAR Model, Economic Growth

\section{Introduction}

Since the reform and opening up, China's economy has achieved rapid development. While traditional manufacturing industry is facing transformation and upgrading, modern service industry has become an important part of economic development. In order to achieve long-term endogenous growth of the Chinese economy in the context of the global economic downturn, it is necessary to inject new impetus into the development of traditional industries and change the traditional investment-driven economic growth model. We must implement industrial transformation policies, achieve stable development of the job market, and rely on modern manufacturing and service industries to vigorously develop 
knowledge-intensive and technology-intensive industries in order to find new economic growth points. Industry is the foundation of employment, and the premise of implementing industrial structure optimization is a stable and reasonable employment structure. At the same time, changes in the industrial structure will also affect the free circulation of labor resources in different fields, and have higher requirements for the quality of laborers. As a developing country, Figure 1 shows that China's economic growth and employment rate have declined significantly in recent years, and the employment growth rate will be negative for the first time in 2019. China's unemployment rate fluctuated around 8.50\% from 2005 to 2012 (Zhang et al., 2016). The above all show that China's current employment situation is getting more and more serious. The main problem focuses on the mismatch between the needs of enterprises and workers. What are the main drivers of current employment changes? What factors will increase the level of employment? What factors do hinder the increase in employment? Combined with the construction of new infrastructure, what are the feasible suggestions for alleviating employment pressure in the current period? Based on this, this article uses China's 1981-2019 time series data to empirically study the main driving force of China's employment changes, with a view to making contributions to alleviating the current excessive employment pressure.

\section{Literature Review}

The current analysis of employment changes mainly focuses on the dual variables, and there is still a lot of room for development in the study of the causal relationship between multiple factors of employment changes. Zou and Shi (2012) believe that the total employment effect of industrial structure upgrade is negative, and industrialization does not constitute a crowding-out effect on employment. Zhu and Xiong (2009) used the DEA method to show that technological

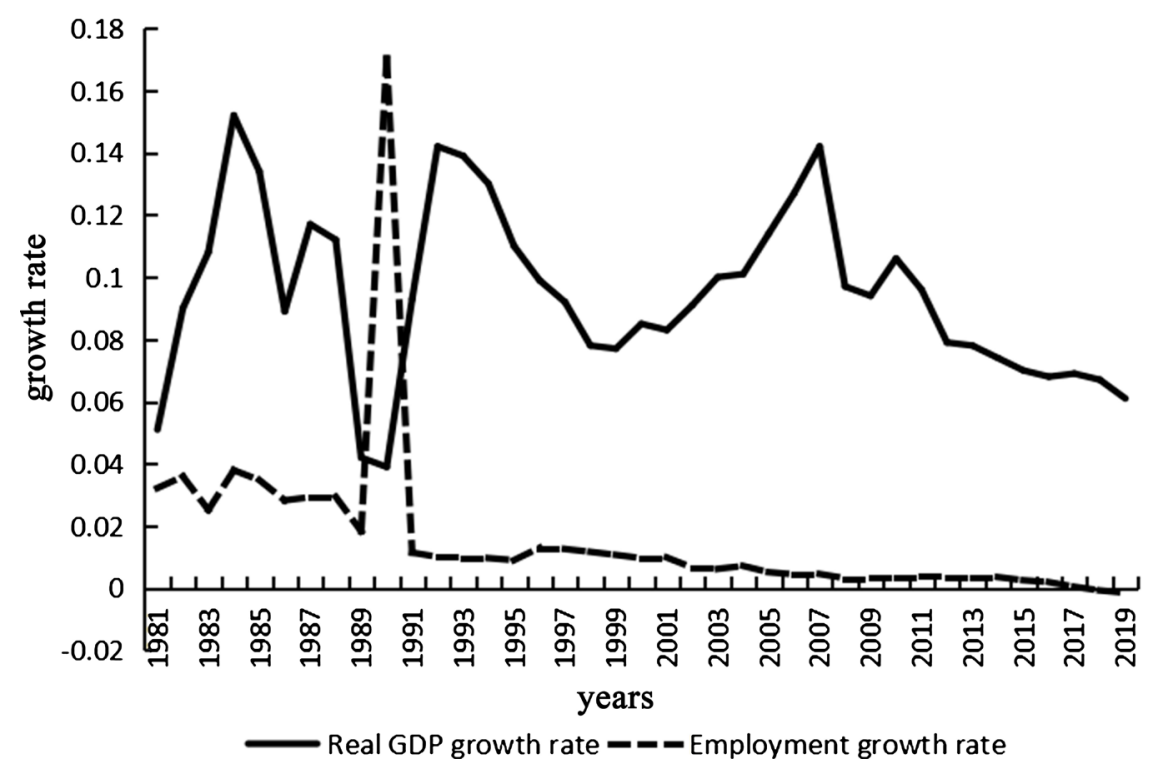

Figure 1. China's economic growth and employment status. 
progress in the tertiary industry is not conducive to promoting employment, and structural unemployment in the optimization of the industrial structure significantly hinders the improvement of employment. Wei P et al. (2015) used the VAR model to study that China's employment structure lags significantly behind the changes in industrial structure, and there is a development imbalance between the two. Shan and Zhang (2018) believe that eastern China's industrial structure and employment structure have the best coordination, while central and western regions lag behind. In addition, some scholars focused on the regional perspective to study the coordinated development of industrial structure and employment structure. Zhang and Gao (2013), Wang and Liu (2014), Li (2016), Dai and Luo (2016) took Liaoning Province, Beijing, Hebei Province and The Yangtze River Delta is the research object, empirical analysis of the coordinated relationship between local industrial structure and employment. Xia et al. (2020) analyzed the coordination problem of China's employment structure and industrial structure from the perspective of space-time coupling, and the results showed that both showed a positive spatial correlation. Li et al. (2005) studied the relationship between economic growth and employment growth based on a theoretical level, and analyzed the differences between the samples of China and the United States using empirical methods, and obtained the interaction mechanism between China's economic growth and employment growth based on employment theory. Chen (2008) believes that China's rapid economic growth has not promoted employment growth, and the effect of economic growth on employment continues to decline. Liu et al. (2015) believes that the employment of secondary and tertiary industries has increased, but from the perspective of employment elasticity, the secondary industry has decreased, while the tertiary industry has increased. This shows that the growth of the tertiary industry has driven employment. The effect is significantly greater than the secondary industry. Kong et al. (2019) based on the theory of labor supply and demand, and through empirical model analysis that human capital investment can significantly promote effective labor supply in the market and improve the quality of employment.

In short, the existing literature focuses on analyzing the relationship between employment structure and economic growth, industrial structure, and capital investment, and rarely analyzes the impact of the three on employment structure changes from national data. Based on this, this article incorporates time series data from across the country and uses the VAR model to study the dynamic mechanism of changes in the employment structure in order to draw corresponding conclusions.

\section{Variables and Models}

This article consists of the following empirical parts: First, take a stable analysis of sequence stability before constructing VAR. If there is no single order of the same order, co-integration research is not possible. It can only be constructed 
after differential processing to construct a VAR model or to construct a VEC model modification study. If the variables have the same order monointegration, the internal cointegration relationship can be studied, and then the VAR analysis method can be constructed. Second, if it is found through research that VAR can be constructed, then it is necessary to specify the most effective amount of lag, and then analyze whether the VAR is stable, and establish the basis for the implementation of impulse response, etc. Thirdly, if all the above processes are realized, Granger causality analysis can be performed to analyze whether the variables are relative to each other. Promoting effect, if there is no relationship, the impulse response analysis cannot be established. Fourth, after the appeal series analysis, the impulse response and variance decomposition analysis can be constructed for research, and finally a conclusion is drawn.

\subsection{Indicators and Data}

Based on a total of 39 years of time series data from 1981 to 2019, construct China's employment elasticity coefficient $(Y)$, per capita GDP $\left(X_{1}\right)$, the extent of the included esteem of the secondary industry to GDP $\left(X_{2}\right)$, the extent of the included esteem of the tertiary industry to GDP $\left(X_{3}\right)$ with the five variable indicators of the whole society's fixed asset investment as a percentage of GDP $\left(X_{4}\right)$, the vector autoregressive show (VAR) is utilized to observationally analyze the changes in China's employment structure. The employment elasticity coeffi$\operatorname{cient}(Y)$ mainly refers to the market's ability to absorb employment, and can reflect China's employment absorptive capacity and changes in employment, in order to effectively reflect the trend of China's employment changes, and express the economic strength of each province and city in terms of GDP per capita. In this paper, the proportion of the added value of the secondary and tertiary industries to GDP is used to represent the changes in industrial structure transformation. The use of the percentage of GDP in the two industrial output values can reflect the impact of industrial structure changes on the employment of China's labor force. Finally, the social capital investment level is expressed by the proportion of fixed asset investment in GDP in the whole society, in order to explain the impact of capital investment on social employment.

The information in this article is basically from the site of the National Bureau of Statistics and "the China Statistical Yearbook", and the time series data from 1981 to 2019 is calculated. Considering that price factors will affect the validity of the empirical results, the GDP index will be used to deflate the nominal GDP; the per capita GDP index will be used to deflate the per capita GDP. Treatment; use the value-added indexes of the secondary and tertiary industries to reduce the value-added of the secondary and tertiary industries respectively. To reduce the impact of inflation, we used the method of consumer price index of Li \& Guan (2017) to deflate the investment of fixed assets in the whole society. Finally, logarithmize the data to get $\ln Y, \ln X_{1}, \ln X_{2}, \ln X_{3}, \ln X_{4}$ to eliminate the heteroscedasticity problem. 


\subsection{Stationary Test}

Because the use of non-stationary time series data modeling may appear "pseudo regression" problems, which will lead to erroneous test results. In arrange to decrease the event of "pseudo regression", the soundness of the first variable is measured utilizing the ADF strategy. The following is the general expression of the model:

$$
\Delta Y_{t}=\alpha_{1}+\alpha_{2} t+(\rho-1) Y_{t-1}+\sum_{i=1}^{m} \beta_{i} Y_{t-1}+\varepsilon_{t}
$$

where $\varepsilon_{t}$ is white commotion, the first theory $\mathrm{H}_{0}: \varepsilon_{t}=1$, indicating that the arrangement $Y$ includes a unit root, and the conclusion is that it is unsteady. In the calculation results, if the value of the $F$ variable is greater than the boundary value, the empirical conclusion is to reject the original conjecture. It means that $Y$ is a stationary process, otherwise the test shows that the original variable is non-stationary.

\subsection{Granger Causality Test}

Granger causality test can experimentally test the impact course between factors. The following formula shows the general Granger causality test formula. In the following formula, $t$ represents time, $k$ represents the maximum lag of the variable, and $\varepsilon_{t}$ represents the random disturbance term in the model. Based on this model, Granger causality test models for $Y, \ln X_{1}, \ln X_{2}, \ln X_{3}$, and $\ln X_{4}$ are established.

$$
\begin{aligned}
& \operatorname{Ln} Y_{t}=A_{10}+\sum_{i=1}^{k} A_{1 i} \operatorname{Ln} Y_{t-1}+\sum_{i=1}^{k} B_{1 i} \operatorname{Ln} X_{t-i}+\varepsilon_{1 t} \\
& \operatorname{Ln} X_{t}=A_{20}+\sum_{i=1}^{k} A_{2 i} \operatorname{Ln} X_{t-1}+\sum_{i=1}^{k} B_{2 i} \operatorname{Ln} Y_{t-i}+\varepsilon_{2 t}
\end{aligned}
$$

\subsection{VAR Model}

The VAR model internalizes the variables to be studied and determines the lag value to analyze the dynamic relationship between the variables. This model can reflect the impact of single variable changes on other internal variables of the system, so as to accurately describe the relationship between variables. The equations studied in this paper are as follows: $Y_{t}=\Phi_{1} Y_{t-1}+\cdots+\Phi_{p} Y_{t-p}+D X_{t}+\varepsilon_{t}$, where $t=1,2, \cdots, T, Y_{t}$ is a $k$-spatial endogenous column vector, $X_{t}$ is an n-spatial exogenous variable, and $p$ is a lag order, and $\Phi_{1}, \Phi_{2}, \Phi_{3}, \cdots, \Phi_{p}$ and $D$ are coefficient matrices that need to be estimated, and $\varepsilon_{t}$ is $k$ as a disturbance term. Before setting up the VAR model, the best lag order should be specified using the rules of AIC and SC, and the stability analysis should be conducted again to determine whether it is suitable to construct the VAR model. Assuming the existence of $\operatorname{VAR}(2)$ model:

$$
\begin{gathered}
X_{t}=A_{1} X_{t-1}+A_{2} X_{t-2}+B_{1} Y_{t-1}+B_{2} Y_{t-2}+\varepsilon_{1 t} \\
Y_{t}=C_{1} X_{t-1}+C_{2} X_{t-2}+D_{1} Y_{t-1}+D_{2} Y_{t-2}+\varepsilon_{2 t}, \quad t=1,2, \cdots, T
\end{gathered}
$$

The impulse response analysis is mainly achieved through the iterative method. When $\varepsilon_{10}=1, \varepsilon_{20}=0, X_{0}, X_{1}, X_{2}, \cdots$ and $Y_{0}, Y_{1}, Y_{2}, \cdots$ can be obtained 
through iteration. The above data are all caused by $X$ shock. The response sequence of $X$ and $Y$. At the same time, when $\varepsilon_{10}=0$ and $\varepsilon_{20}=1$, the corresponding shock reflection function can be obtained (Gao, 2006).

\section{Empirical Analysis}

According to the above indicators and measurement models, the relevant statistical data can be calculated to obtain the following contents.

\subsection{ADF Unit Root Test}

From Table 1, we know that both $\ln X_{1}$ and $\ln X_{4}$ are accepting the null hypothesis, indicating that the original sequence of the two is not stable, but all the variables obtained after the first-order difference analysis are stable variables. The $\ln X_{2}, \ln X_{3}$ and $Y$ sequences all deny the original guess in the degree, and are expressed as stationary sequences. In this regard, considering that at first the variables are not integers of the same order, it is not possible to conduct cointegration analysis, But Granger causality holds that analysis is suitable for the construction of VAR models.

\subsection{Determine the Optimal Lag Order}

As shown in Table 2, after lagging the model by 2 periods, the optimal lag order can be expressed as 2 according to the LR and SC criteria, and after 4 periods by the FPE, AIC, and HQ criteria, the optimal lag order can be expressed as 4. According to the principle of maximum determination (Qiang, $\mathrm{He}, \& \mathrm{Wu}, 2010$ ), this paper establishes the VAR(4) model. To observationally analyze whether there's a causal relationship between the factors within the $\operatorname{VAR}(4)$ variable show, the Granger causality test is utilized to analyze the relationship between the two sets.

\subsection{Granger Causality Test}

As shown in Table 3, there is no causal relationship between $Y$ and $D \ln X_{1}$. Analysis

Table 1. Stationary test.

\begin{tabular}{|c|c|c|c|c|c|c|}
\hline \multirow{2}{*}{ variable } & \multirow{2}{*}{$(\mathrm{C}, \mathrm{T}, \mathrm{L})$} & \multirow{2}{*}{ ADFStatistics } & \multicolumn{2}{|c|}{ Critical value } & \multirow{2}{*}{$p$ value } & \multirow{2}{*}{ conclusion } \\
\hline & & & $1 \%$ & $5 \%$ & & \\
\hline $\ln X_{1}$ & $(\mathrm{C}, 0,4)$ & -1.6264 & -3.6394 & -2.9511 & 0.4585 & Non-stationary \\
\hline $\ln X_{2}$ & $(0,0,2)$ & $-2.4144^{\star \star}$ & -2.6308 & -1.9504 & 0.0172 & smooth \\
\hline $\ln X_{3}$ & $(\mathrm{C}, \mathrm{T}, 2)$ & $-5.1290^{* * *}$ & -4.2350 & -3.5403 & 0.0010 & smooth \\
\hline $\ln X_{4}$ & $(0,0,2)$ & 2.4258 & -2.6308 & -1.9504 & 0.9954 & Non-stationary \\
\hline$Y$ & $(\mathrm{C}, 0,9)$ & $-43.0556^{* * *}$ & -3.6793 & -2.9678 & 0.0001 & smooth \\
\hline$d \ln X_{1}$ & $(\mathrm{C}, \mathrm{T}, 3)$ & $-3.7998^{\star *}$ & -4.2529 & -3.5485 & 0.0289 & smooth \\
\hline$d \ln x X_{4}$ & $(\mathrm{C}, 0,1)$ & $-3.6202^{\star *}$ & -3.6268 & -2.9458 & 0.0102 & smooth \\
\hline
\end{tabular}

The "*”, " **” and "***»" referred to in this article mean that the variables are significant at the levels of " $10 \%$ ", " $5 \%$ " and " $1 \%$ ". The " $d$ " or " $D$ " involved in the text all represent the differential form of the variable 
Table 2. Optimal lag order.

\begin{tabular}{ccccccc}
\hline Lag & LogL & LR & FPE & AIC & SC & HQ \\
\hline 0 & 161.219 & NA & $7.03 \mathrm{E}-11$ & -9.190 & -8.965 & -9.113 \\
1 & 380.127 & 360.554 & $7.96 \mathrm{E}-16$ & -20.596 & -19.249 & -20.136 \\
2 & 426.497 & $62.736^{*}$ & $2.51 \mathrm{E}-16$ & -21.853 & $-19.384^{*}$ & -21.011 \\
3 & 461.064 & 36.600 & $1.89 \mathrm{E}-16$ & -22.416 & -18.824 & -21.191 \\
4 & 506.083 & 34.426 & $1.10 \mathrm{e}-16^{*}$ & $-23.593^{*}$ & -18.880 & $-21.986^{*}$ \\
\hline
\end{tabular}

Table 3. Granger causality test.

\begin{tabular}{cccccc}
\hline Null hypothesis & Lag & observations & Chi-sq & $p$ value & relationship \\
\hline$Y$ is not Granger causal cause of $D \ln X_{1}$ & 4 & 34 & 3.6390 & 0.4571 & No \\
$D \ln X_{1}$ is not Granger causal cause of $Y$ & 4 & 34 & 2.7835 & 0.5947 & No \\
$Y$ is not Granger causal cause of $\ln X_{2}$ & 4 & 34 & 9.2329 & 0.0555 & Yes \\
$\ln X_{2}$ is not Granger causal cause of $Y$ & 4 & 34 & 8.5515 & 0.0733 & Yes \\
$Y$ is not Granger causal cause of $\ln X_{3}$ & 4 & 34 & 3.2847 & 0.5114 & No \\
$\ln X_{3}$ is not Granger causal cause of $Y$ & 4 & 34 & 8.2279 & 0.0836 & Yes \\
$Y$ is not Granger causal cause of $D \ln X_{4}$ & 4 & 34 & 19.0466 & 0.0008 & Yes \\
$D \ln X_{4}$ is not Granger causal cause of $Y$ & 4 & 34 & 5.9215 & 0.2051 & No
\end{tabular}

shows that $Y$ and $\ln X_{2}$ have a two-way interactive connection, that is, $Y$ has an influence on $\ln X_{2}$, and $\ln X_{2}$ also has a role on $Y ; Y$ and $\ln X_{3}$ have a one-way interactive connection, that is $Y$ cannot affect $\ln X_{3}$, but $\ln X_{3}$ can affect $Y ; Y$ and $D \ln X_{4}$ also have a one-way interactive connection, $Y$ can function $D \ln X_{4}$, but $D \ln X_{4}$ cannot affect $Y$.

\subsection{Stationary Test}

Based on the previous research results, a $\operatorname{VAR}(4)$ model is constructed to analyze the dynamic fluctuation relationship between the five variables, that is, given a unit shock of the independent variable, the response graph of the variation range of the dependent variable is obtained. As shown in Figure 2, to test whether the model is stable, the results show that the roots of all variables in the VAR(4) model are within the unit circle, indicating that the model has passed the stability test.

\subsection{Impulse Response Function}

Use Eviews 8.0 software to perform 1 unit shock on $D \ln X_{1}, \ln X_{2}, \ln X_{3}$, and $D \ln X_{4}$ respectively. The resulting impulse response image of $Y$ is shown in Figure 3. The horizontal coordinate refers to the value of each future period, and the vertical coordinate refers to the impact of $Y$ on each variable the reflected image made.

As shown in Figure 3, for the VAR(4) model, given a unit of $D \ln X_{1}$ shock, the employment elasticity coefficient has a positive fluctuation trend in the current 


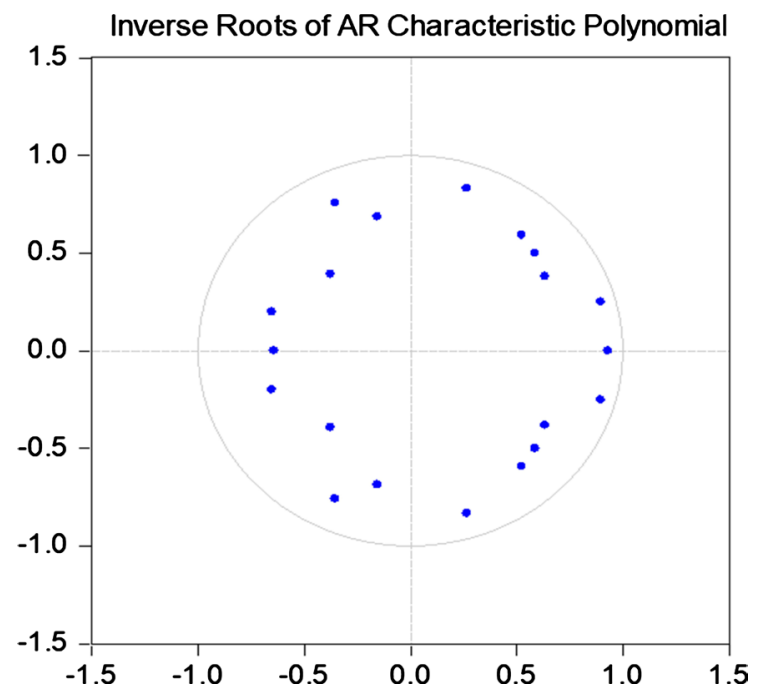

Figure 2. Model stationarity test. Both the horizontal axis and the vertical axis in the image represent the unit scale of the unit circle.

Response to Cholesky One S.D. Innovations ?2 S.E.
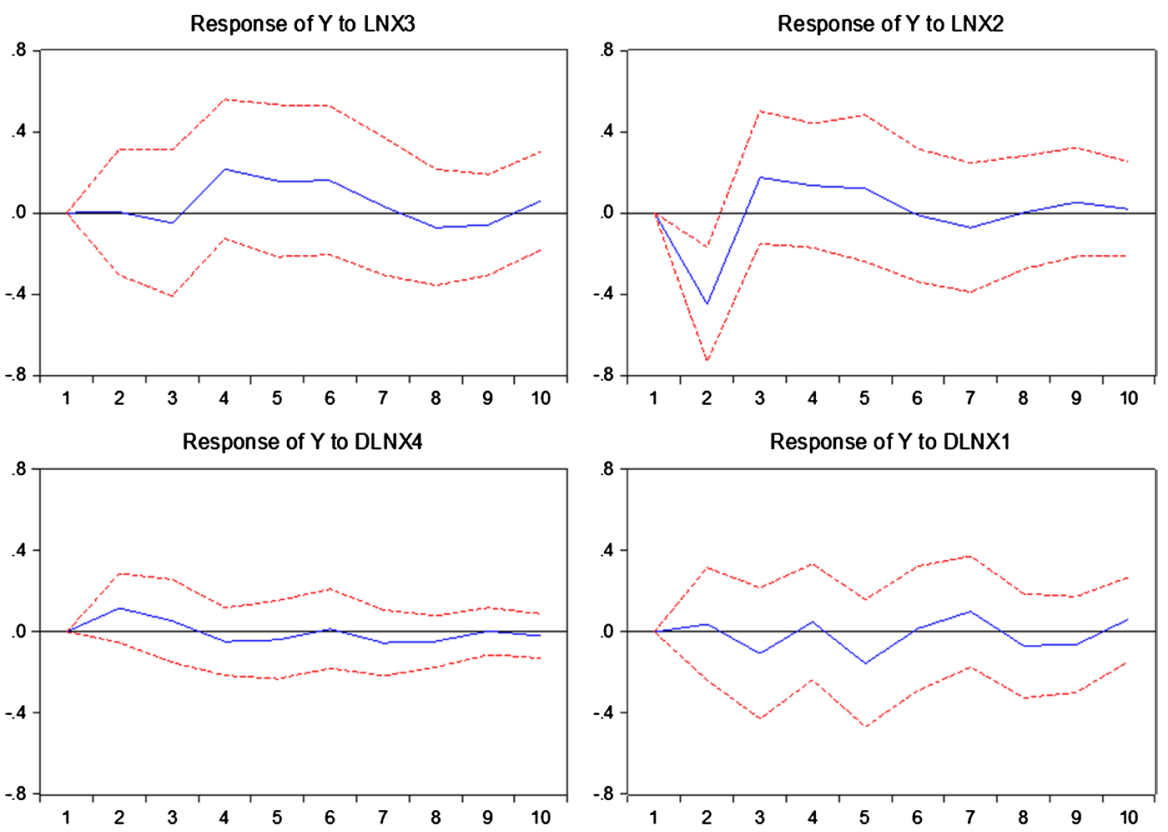

Figure 3. Impulse response function analysis. The horizontal axis represents the unit variation of the impact variable, and the vertical axis represents the unit variation of the impacted variable.

period, then reaches the maximum value in the second period, then there is a decline, and in the third period it achieves the smallest negative value. It reached the maximum value in the $4^{\text {th }}$ period, and then reached the bottom after the $5^{\text {th }}$ period reached the minimum value, so as to maintain the fluctuation state on the 0 scale line. China's economy is growing rapidly, and the demand for labor is strong in the short term. Therefore, the size of economic growth will affect the supply and demand of the labor market. The labor market is often saturated, and the demand for labor in various industries in the market will overheat with 
economic fluctuations, which will prevent short-term overheating of the labor market supply, which will cause the employment rate to fall and the unemployment rate to rise, so that even the employment elasticity coefficient will be negative Situation. But this short-term shock will only affect the employment market to a small extent. When the period stretches, economic growth can have a positive relationship with the employed labor force, that is, economic development can absorb the supply of labor and promote employment.

As shown in Figure 3, after a unit shock to the proportion of secondary industry $\left(\ln X_{2}\right)$, the employment elasticity coefficient $(Y)$ showed a significant negative change, reaching the lowest point in the second period, and then rapidly rising and reaching in the third period. The highest point has since stabilized in positive fluctuations, and in the sixth and seventh periods there was a slight negative fluctuation, but then immediately rebounded to positive fluctuations. As the number of periods increases, the employment elasticity coefficient will stabilize above the zero mark and approach the zero mark. It can be seen from this that the rapid expansion of China's secondary industry in the short term will not immediately absorb labor, but will cause excessive labor unemployment. Because the secondary industry is mainly composed of manufacturing industries that require a lot of investment, short-term expansion will invest a lot of capital to update technology to promote hardware construction, and will not immediately absorb labor and will squeeze some labor wages, resulting in dissatisfaction of some workers. This change resulted in unemployment. However, after reaching the mid-to-late period, enterprises in the secondary industry will continue to promote the economies of scale and absorb a large amount of high-tech and low-end labor, so the labor elasticity coefficient will quickly rebound to positive fluctuations. However, with the continuous improvement of the secondary industry represented by the manufacturing industry for a long time, most enterprises are moving toward capital and knowledge-intensive development, that is, enterprises will invest a lot of capital to update equipment and improve technology to improve production efficiency and reduce production costs. This process will have a substitution effect on the labor force, which in turn will affect labor employment. Therefore, the effect of long-term secondary industry development on employment substitution will continue to increase, and the ability to absorb labor will continue to weaken, that is, the pulse effect graph tends to fluctuate on the 0 scale. In short, the secondary industry will hinder labor employment at the beginning of the period. In the medium term, it will significantly promote labor employment and has a strong labor absorption feature. However, as the period (year) is lengthened, this positive effect tends to be flat, that is; the labor absorption effect of the secondary industry is gradually weakening, and the driving effect on employment is limited.

As shown in Figure 3, given the impact of 1 unit in the tertiary industry $\left(\ln X_{3}\right)$, the employment elasticity coefficient has not changed significantly, that is, there is a certain lag effect. There was a small negative volatility in the second period, 
but then it bottomed out to a high level in the third period, and maintained a higher level of volatility in the positive range. Until the beginning of the $8^{\text {th }}$ period, there was a negative change, but then to the $9^{\text {th }}$ period, there was a significant positive change trend. In short, the tertiary industry has a positive effect on a few pages of elasticity coefficient, which will promote labor employment. Specifically, the tertiary industry is dominated by the service industry, and the demand for capital is not high, so the short-term labor substitution effect is not obvious. The short-term tertiary industry has a relatively large demand for labor, and the industry's initial requirements for labor are not high, so it can absorb a large number of labor. However, in the medium term, the development of the tertiary industry has entered a normative stage, and the quality requirements of the overall practitioners are gradually increasing. High-quality workers will continue to enter and gather development, while low-quality workers will be gradually rejected, resulting in the tertiary industry absorbing employment capacity. The weakening trend is reflected in the impulse response graph which shows a negative change in the $8^{\text {th }}$ to $9^{\text {th }}$ periods. However, in the later period, the tertiary industry's absorption of labor will show a stable and positive trend. The tertiary industry represented by the service industry not only has a strong ability to absorb labor, its spatial effect also has a leading role in other regions and industries, so its employment effect is obvious stronger than the secondary industry. This conclusion is consistent with the theory of "Party-Clark", that is, China is currently mainly developing secondary and tertiary industries, and its industrial structure is gradually moving from "one, two, and three" forms to "three, two, and one" forms.

As shown in Figure 3, when a unit of capital investment $\left(D \ln X_{4}\right)$ impacts by 1 unit, the employment elasticity coefficient gradually increases in the first period, reaches the highest point in the second period, and then begins to decline until it begins to appear negative at the end of the third period. Change, and thereafter stabilized at a negative value. This shows that with the increase in fixed asset investment, employment can be promoted in the short term, but employment in the medium and long term is hindered. Because enterprises need to invest a lot of manpower, material and financial resources to develop and grow, but when the enterprise develops to a certain scale of economy, the replacement of equipment and technology replaced by capital investment gradually strengthens the substitution effect on labor, which causes the employment rate to decline. In short, after the expansion of the enterprise scale, under the condition of the owner's pursuit of profit maximization, its substitution effect is stronger than the inter-scale effect, and the demand for labor force gradually decreases. Therefore, expanding capital investment in China will cause China's employment rate to fall and the unemployment rate to rise.

\subsection{Variance Decomposition}

Through impulse response function analysis, the effect of changes in industrial 
structure, economic growth, and capital investment on employment can be effectively obtained, and the specific analysis of the variables on the employment elasticity coefficient $(Y)$ needs to be achieved by the variance decomposition method. As shown in Table 4, taking the data lagging 20 periods, the initial $Y$ is $100 \%$. As the period lengthens, its own contribution to the amount gradually decreases, and it stabilizes at about $53 \%$ in the $20^{\text {th }}$ period. In terms of economic growth $\left(D \ln X_{1}\right)$, the proportion of the secondary industry $\left(\ln X_{2}\right)$, the proportion of the tertiary industry $\left(\ln X_{3}\right)$ and the capital investment $\left(D \ln X_{4}\right)$, the contribution of $D \ln X_{1}$ to the $20^{\text {th }}$ period is stable at about $6 \%$, and $\ln X_{2}$ is stable at $25 \%$, $\ln X_{3}$ is stable at about $11 \%$, and $D \ln X_{4}$ is stable at about $2 \%$. In short, the study believes that in addition to the contribution of the employment elasticity coefficient itself, the proportion of secondary and tertiary industries contributes to it at a higher level, while economic growth and capital investment contribute to it at a lower level. Based on this, improving the level of industrial structure optimization has an important role in promoting employment.

\section{Conclusion and Recommendations}

Using empirical methods to analyze the changes in China's employment elasticity coefficient, it is concluded that China's overall employment problem is severe at this stage, and the following conclusions are drawn based on impulse response and variance decomposition tests: Firstly, the level of economic growth and the increase in the proportion of secondary and tertiary industries are important forces driving employment, while capital investment is not significant for increasing employment. Secondly, in the short term, increasing the proportion of the secondary industry will have a negative impact on employment, while increasing the proportion of the tertiary industry will have a significant effect on the employment effect. Increasing capital investment can promote labor employment. Finally, in the long run, increasing the proportion of secondary and tertiary industries has a positive effect on employment promotion. However, as

Table 4. Variance decomposition.

\begin{tabular}{ccccccc}
\hline Period & S.E. & $Y$ & $L N X_{3}$ & $L N X_{2}$ & $D L N X_{4}$ & $D L N X_{1}$ \\
\hline 2 & 0.769 & 63.126 & 0.001 & 34.334 & 2.301 & 0.238 \\
4 & 0.912 & 59.764 & 5.884 & 30.267 & 2.265 & 1.820 \\
6 & 0.980 & 55.657 & 10.325 & 27.734 & 2.150 & 4.133 \\
8 & 1.008 & 54.998 & 10.385 & 26.727 & 2.551 & 5.339 \\
10 & 1.018 & 54.044 & 10.862 & 26.527 & 2.548 & 6.019 \\
12 & 1.024 & 53.765 & 11.145 & 26.414 & 2.573 & 6.103 \\
14 & 1.031 & 53.896 & 11.012 & 26.359 & 2.579 & 6.153 \\
16 & 1.037 & 54.009 & 11.041 & 26.155 & 2.556 & 6.240 \\
18 & 1.041 & 53.843 & 11.339 & 26.031 & 2.547 & 6.240 \\
20 & 1.043 & 53.927 & 11.355 & 25.941 & 2.545 & 6.232 \\
\hline
\end{tabular}


the number of periods in the secondary industry increases, the employment effect gradually increases from a positive value to zero. Tertiary industry employment promotion is stronger than secondary industry. In the long run, increasing the level of capital investment significantly inhibited labor employment.

Based on this, this article puts forward the following policy recommendations: Firstly, under the background of economic transformation, China's overall economic growth rate has slowed down, and the role of economic growth in promoting employment has gradually weakened, while improving industrial structure optimization can inject new vitality into promoting employment in the labor market. It is necessary to lay out industries according to local conditions, formulate industrial plans in various regions by regions to rationally develop manufacturing and service industries, and take "innovative development" as the goal to attract talents and enterprises from strategic emerging industries to gather and develop, and increase the proportion of regional secondary and tertiary industries. Secondly, avoid excessive capital investment in construction, in the context of new infrastructure construction policies, gradually phase out backward production capacity, and avoid pursuing a single GDP growth rate and ignoring economic high-quality development goals. Thirdly, improve the labor market mechanism and provide social security for labor employment. The government should strengthen education investment, develop vocational education and higher education in a rational manner, allocate educational resources reasonably and provide preferential policies. At the same time, it is necessary to implement the talent guarantee mechanism and improve the labor market mechanism, build an efficient and convenient job exchange platform, and provide convenience for job seekers while finding jobs and reducing burdens.

This article uses the VAR model to analyze the main drivers of China's employment changes, but there are several deficiencies in the following aspects: Firstly, considering that the time series data used in China are not based on data from various regions of China. Therefore, the panel model can be used for more specific analysis in the future. Secondly, considering the evolution of the spatial and temporal pattern, and with the development of spatial econometrics, using spatial measurement methods to analyze labor employment will be an important research field in the future. Thirdly, with the development of intelligent technology, such as Cai \& Chen (2019) study the effect of intelligence on market employment. The future needs to analyze the impact of industrial intelligence on labor employment from the perspective of intelligence.

\section{Conflicts of Interest}

The author declares no conflicts of interest regarding the publication of this paper.

\section{References}

Cai, Y. Z., \& Chen, N. (2019). Artificial Intelligence and High-Quality Growth and 
High-Quality Employment under the New Technology Revolution. Quantitative Economic Technology and Economic Research, 36, 3-22.

Chen, Z. (2008). An Empirical Study on the Relationship between Economic Growth and Employment Growth. The Economist, No. 2, 90-95.

Dai, Z. M., \& Luo, Y. (2016). An Analysis of the Coordination of Industrial Structure and Employment Changes in 16 Cities in the Yangtze River Delta. Economic Survey, 33, 125-130.

Gao, T. M. (2006). Econometric Analysis Method and Modeling (pp. 267-318). Beijing: Tsinghua University Press.

Kong, W., Lian, Y. S., \& Liu, C. (2019). Human Capital Investment, Effective Labor Supply and High-Quality Employment. Economic Issues, No. 5, 9-18.

Li, J. F., Wang, D. J., \& Song, X. J. (2005). Research on the Relationship between Economic Growth and Employment Growth-Re-Judgment of the Correlation between the Two. China Soft Science, No. 1, 64-70.

Li, X., \& Guan, H. J. (2017). Analysis of the Mechanism of the Impact of Human Capital Accumulation on My Country's Economic Growth. Audit and Economic Research, 32, 100-108.

Li, Z. W. (2016). An Empirical Analysis of the Coordinated Development of Industrial Structure and Employment Structure in Hebei Province-Based on the Perspective of Human Capital Theory. Economy and Management, 30, 42-48.

Liu, W., Cai, Z. Z., \& Guo, Y. X. (2015). Research on the Relationship between Economic Growth and Employment in China at This Stage. Economic Science, No. 4, 5-17.

Qiang, L. F., He, N., \& Wu, Y. M. (2010). Research on the Interactive Relationship between Bank of China Credit, Real Estate Prices and Macroeconomics-An Empirical Analysis Based on VAR Model. Statistics and Information Forum, 25, 75-80.

Shan, L., \& Zhang, T. (2018). A Study on the Spatiotemporal Evolution of the Coordination between Industrial Structure and Employment Structure in China. Chinese Population Science, No. 2, 39-49.

Wang, S. G., \& Liu, H. (2014). Coordination Analysis of Industrial Structure and Employment Structure in Beijing. Economics and Management Research, No. 7, 85-90.

Wei, P., Ren, A. R., \& Li, J. (2015). Research on the Relationship between Industrial Structure and Employment Structure in China-Based on the Perspective of Coordination and Impact. Exploration of Economic Problems, No. 11, 54-62.

Xia, S. Y., Zhao, Y., Xu, X., \& Liu, X. J. (2020). The Evolution of the Spatiotemporal Pattern of the Coordination of Employment Structure and Industrial Structure in China. East China Economic Management, 34, 73-80.

Zhang, J., Xu, L., \& Zhang, H. (2016). Uncovering the Truth about Chinese Urban Unemployment Rates: 2005-2012. China and World Economy, 24, 1-18.

https://doi.org/10.1111/cwe.12178

Zhang, K. S., \& Gao, D. F. (2013). Study on the Coordination Relationship between Industrial Structure and Employment Structure in Liaoning Province. Chinese Population Science, No. 6, 80-90.

Zhu, Y., \& Xiong, S. M. (2009). Empirical Research on the Effect of Technological Progress and Industrial Structure Changes on Employment in My Country. Quantitative Economic Technology Economic Research, 26, 107-119.

Zou, Y. N., \& Shi, T. C. (2012). Analysis of Employment Effect of Industrial Structure Upgrade. Shanghai Economic Research, 24, 3-13. 